\title{
Tactics in tennis doubles: analysis of the formations used by the serving and receiving teams
}

\author{
Kocib T. a, ${ }^{*}$, Carboch, J. ${ }^{a}$, Cabela M. ${ }^{a}$, Kresta J. ${ }^{b}$ \\ a Faculty of Physical Education and Sport, Charles University, Czech Republic \\ b Faculty of Education, Jan Evangelista Purkyne University, Czech Republic \\ *Corresponding author email: kocib@ftvs.cuni.cz \\ DOI: https://doi.org/10.34256/ijpefs2026 \\ Received: 12-04-2020, Accepted: 06-06-2020
}

\begin{abstract}
There are several tactical variants that can be used by the serving and receiving teams before the serve is struck in tennis doubles. The goal is to analyse the frequency and efficiency of the tactical variants of the serving and receiving teams in doubles at the elite level. We analysed 1067 points in 18 doubles matches in professional men's top-level tennis tournaments. Next to the Classical formation, the I-formation was used in $46 \%$ of points when players hit the first serve and in $41 \%$ of cases when the point started with the second serve. Both formations had very equal efficiency, both after the first and second serve. The receiving team preferred a formation where both players were positioned at the baseline (53\%) when returning the first serve, but only in 18 $\%$ of points when they faced the second serve. The results summarize strategies and specific tactical variants in current game performance of male doubles at the top tennis level and the results can help to set a default set-up of training volumes of these game situations. The coaches can use the information and adjust the practice sessions according to the tactical demands of professional tennis.
\end{abstract}

Keywords: Game performance, Strategy, I-formation, Classical formation, Notational analysis

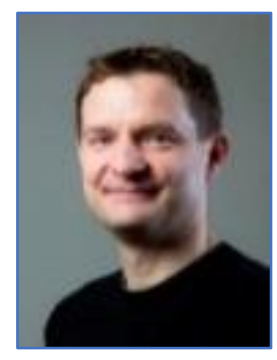

Mgr. Tomas Kocib is a lecturer at Department of Sport Games, Faculty of Physical Education and Sport, Charles University. $\mathrm{He}$ graduated at the this faculty. His research interest is psychology and game performance in tennis. He is also as a tennis coach and contributes on the education of tennis coaches in the Czech Republic.

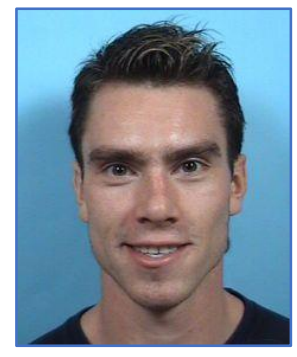

Dr. Jan Carboch Ph.D. is a lecturer and sport scientist at Department of Sport Games, Faculty of Physical Education and Sport, Charles University. He graduated and finished his PhD. at the same University. His dissertation thesis was focused on visual perception and anticipation in tennis. His research interest is game performance and analyses, anticipation and visual perception in sport games and qualitative analyses of human movement. He is also involed in proffesional tenins as a tennis official.

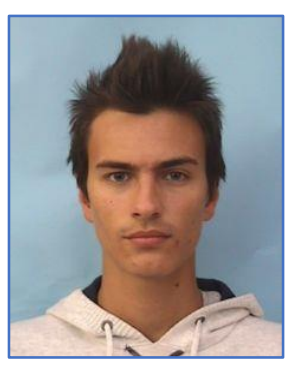

Mgr. Matej Cabela is a recent graduate of the Faculty of Physical Educatiion and Sport, Charles University. His master's thesis was focused on tactics and game performance in tennis. He has obtained a coaching licence and is a tennis coach.

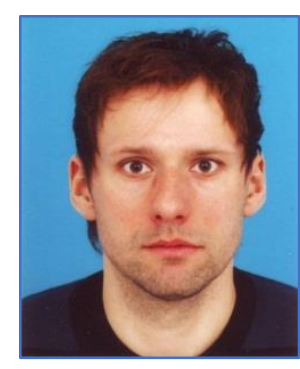

Dr. Jan Kresta Ph.D. works as a lecturer and sport scientist at Department of Physical Edication and Sport, Faculty of Education, J. E. Purkyne University. He graduated and finished his Ph.D. at the Charlers University. His dissertation thesis was focused on refereeing in sports games. His research interest is referee's performance in sport games. He is also involed in proffesional futsal as an official. 


\section{Introduction}

Tennis is an individual sport (singles), but we have seen the fundamental development of its second discipline - doubles, in the last twenty years. This includes, for example, doubles rules, players' performance, fitness and game strategy. Doubles is important not only in team matches (Davis Cup, Fed Cup), but also for the overall development of individuals. This is evidenced by more frequent involvement of singles players in doubles competitions. It has been shown that juniors players use different serve tactics compared to men [1], or the winners usually make less unforced errors while hitting shots from the offensive zone [2]. To adapt the players to these situations, some modification for young beginning players (under 10 years old), such as ball or court size, were expanded recently that can have positive impact on their tennis development [3].

The strategy of doubles is addressed by many authors. [4-7]. That includes a proper communication within the team [8]. There are specific strategic types of doubles players (playing styles) defined by Cayer [9] as well as the specific tactical variants, e.g. the Iformation of the serving team. One of the turning points of modern doubles and strategy is the tactical variant I-formation that has been implemented into the game performance in professional tennis. This is followed by other studies [10-13], which examined current doubles strategy. When analysing strategy, we are always forced to some simplification. That is why we focus on the effectiveness of the play, especially on the efficiency, which can be determined by the percentage of points won after the game activity. Our study is focused on game activities that relate to the position of the team before the start of the point.

Players can use several tactical variants in doubles before the serve is executed [9]. The serving team can use the Classical formation, I-formation or Australian formation; for the receiving team we distinguish formations where both players are at the baseline or when the receiver is at the baseline and his partner is positioned at the net. These categories are described in detail by Cayer [9] or Carboch [10]. The serving side (deuce or ad court) need to be considered while observing serving and returning strategy. This is due to different angles of ball flight trajectory and ball spin.

On average, a doubles match consists of 10.5 games per set and 5.5 points per game at the male top-level [14]. Previous research [11] at the lower international level tournaments revealed, that the Classical formation massively prevails both in male and female matches. Female players did not use Iformation at all, but the Australian formation has very rarely occurred. Male players, next to the Classical formation, used only the I-formation (in $3 \%$ of cases) and mostly from the ad court. However, this Iformation from the ad court was more efficient compared to the Classical formation. It is not clear, how frequently are the tactical variants used on the top-level. The aim is to analyse the frequency and efficiency of the tactical variants of the serving and receiving teams in doubles at the elite level.

\section{Methods}

\subsection{Participants}

In total, we observed 18 sets in 18 doubles matches in professional men's tennis tournaments. Altogether we analysed 195 games (1067 points). The matches were played on the ATP circuit tournaments $(n=8)$ in 2018, ATP Masters tournament $(n=6)$ in 2018 and the Australian Open $(n=4)$ in 2019. All the matches were played on a hard court (medium pace surface) and finished properly (no retirements). The participants were 18 teams (in total 33 players, where 28 of them were right handed and 5 left handed. The participants were $32.73 \pm 3.88$ years old. were $188.6 \pm 13.7 \mathrm{~cm}$ tall, weighted $81.8 \pm 9.1 \mathrm{~kg}$ and their mean ATP doubles ranking was $53.2 \pm 6.9$. We used convenience sampling and chose the players (teams) from the top ranking list and also the top singles players playing doubles, who can perform on the same level as the top doubles players. One observed set (excluding match tie-break) was randomly chosen from each match. This study was approved by the Ethics committee of the Charles University, Faculty of Physical Education and Sport.

\subsection{Material and procedures}

Matches were recorded from the TV and internet broadcast and consequently analysed. The quality of the video recordings was considered appropriate for the consequent analysis. An expert evaluator analysed the matches in a calm environment without being disturbed and without time stress. He was able to pause or review the match if he needed to judge the situation correctly [15]. Followingly, the observed variables were recorded into a spreadsheet prepared in advance. The observed variables were the tactical variants and its efficiency of each team 
(serving or receiving team). The serving team can use a Classical formation, I-formation or Australian formation, while the receiving team can be positioned with one player at the base line and one player at the net; or both players at the baseline. We focused on the frequency of each these tactical variants and its effectivity (i.e. which team won the point) when the ball got into play (if the server missed the first, we did not record the formation and we used the formation that was consequently used by the teams during the second serve).

\subsection{Data analysis}

The data were evaluated using the mathematical and statistical methods. A frequency analysis was used, and the data are reported in relative values. Relative efficiency is calculated for the first and second serves separately, i.e. the ball landed in the correct field (if the server missed the first serve, the point then continues with the second serve). The team was observed in all the points played. The measured data were divided into the first and second serve, both for the serving and receiving team (whether the server missed the first serve or not and the rally started with the first serve or the second serve). For the serving team, we also analysed the serving side of the serving team (deuce or ad court).

\section{Results}

The most important finding was a very frequent use of the I-formation. The I-formation occurred in $46 \%$ of all the serving points. This necessarily results in a decrease in the frequency of the Classical formation to $54 \%$. We did not record any Australian formation of the serving team. Table 1 shows the relative frequencies of the tactical variants of the serving team. No other formation of the serving team was recorded, so only two variants appeared in our study. Moreover, the I-formation and Classical formation appear to be very equal in terms of efficiency. This table is important for tennis practice as it reflects the current trend in the representation of specific situations on serve. The frequencies of the tactical variants after the second serve are lower because this situation occurs only if the server misses the first serve. This happened in $30 \%$ of all points. That reveals that the top doubles teams have $70 \%$ of the first serve in. Next, after the second serve we can see an interesting change of the ratio between the Classical formation and I-formation compared to the first serve. The Classical formation was preferred to the I-formation by the serving teams in the ratio $1.2: 1$ during the first serve, and 1.5: 1 during the second serve. The relatively high percentage of the Iformation is probably the most important outcome of the study, so we give it an even more details table 2 and below. For the practical use of the results, it is important to know the ratio of the tactical variants during the first and second serve of the elite tennis players (counting all the serves together) - the Classical formation is $37 \%$ and the I-formation $33 \%$ (both for the first serve). For the second serve, the Classical formation is $18 \%$ of cases and the Iformation $12 \%$. These values can help to set a default set-up of training volumes of these game situations.

Important factor is also the court side of serving team (deuce or ad court). The results shows that the I-formation is used more when serving from the deuce court (table 2). We can see greater disparity of the I-formation usage between the first serve (55\% to $38 \%$ ) and the second serve (46 to $36 \%$ ). The highest efficiency was after the first serve from the deuce court and the lowest after the second serve from the ad court. Notably, the I-formation was more efficient from the deuce court after the first serve, but from the ad court after the second serve.

The receiving team used two formations, depending on the receiver's partner position, i.e. at the net near the service line; or at the baseline (both players at baseline). No other formation of the receiving team occurred. The most important finding occurs (in $53 \%$ ) when receiving the first serve and the receiving team is positioned with both players at the baseline formation. This has become the most common option, but only when the opponent executed the first serve. However, when the serving team used the second serve, the frequency of both players at the baseline decreased to "only" $18 \%$. Table 3 shows the frequencies of tactical variants used by the receiving team when returning the first and second serve respectively. These receiving formations were not entirely equivalent in terms of efficiency. When receiving the first serve, the formation of both players at the baseline had $4 \%$ higher efficiency compared to formation, where the receiver's partner was positioned at the net; but in contrast reached $5 \%$ less efficiency when returning the second serve. For the same reasons as the frequency of the serving team formations, this table shows some importance for training planning of the receiving formations. 
Table 1 Frequency and efficiency of tactical variants of the serving team

\begin{tabular}{|l|c|c|c|c|c|c|}
\hline & \multicolumn{2}{|c|}{ Classical formation } & \multicolumn{2}{c|}{ I-Formation } & \multicolumn{2}{c|}{ Australian formation } \\
\hline & Frequency & Points won & Frequency & Points won & Frequency & $\begin{array}{c}\text { Points } \\
\text { won }\end{array}$ \\
\hline $1^{\text {st }}$ serve (\%) & 53.7 & 80.3 & 46.3 & 81.5 & - & - \\
\hline $2^{\text {nd }}$ serve (\%) & 59.2 & 57.2 & 40.8 & 56.4 & - & - \\
\hline
\end{tabular}

Table 2 Details of the I-formation usage from the deuce and ad court

\begin{tabular}{|c|c|c|c|c|c|c|}
\hline & \multicolumn{3}{|c|}{ Frequency } & \multicolumn{3}{c|}{ Points won } \\
\hline & Both sides & $\begin{array}{c}\text { Deuce } \\
\text { court }\end{array}$ & $\begin{array}{c}\text { Ad } \\
\text { court }\end{array}$ & Both sides & $\begin{array}{c}\text { Deuce } \\
\text { court }\end{array}$ & $\begin{array}{c}\text { Ad } \\
\text { court }\end{array}$ \\
\hline $1^{\text {st }}$ serve (\%) & 46.3 & 54.6 & 38.4 & 81.5 & 88.3 & 73.5 \\
\hline $2^{\text {nd }}$ serve (\%) & 40.8 & 45.8 & 35.8 & 56.4 & 67.9 & 44.6 \\
\hline Overall (\%) & 43.6 & 50.2 & 37.1 & 69.0 & 78.1 & 59.1 \\
\hline
\end{tabular}

Table 3 Frequency and efficiency of tactical variants of the receiving team

\begin{tabular}{|l|c|c|c|c|}
\hline & \multicolumn{2}{|c|}{ Baseline/net } & \multicolumn{2}{c|}{ Both at baseline } \\
\hline & Frequency & Points won & Frequency & Points won \\
\hline $1^{\text {st }}$ serve (\%) & 46.7 & 27.6 & 53.3 & 31.6 \\
\hline $2^{\text {nd }}$ serve (\%) & 81.6 & 50.2 & 18.4 & 44.9 \\
\hline
\end{tabular}

\section{Discussion}

The aim was to analyse the frequency and efficiency of the tactical variants of the serving and receiving teams in doubles at the elite level. The most interesting finding is the frequency of the I-formation used by the serving teams. If we compare the results to previous studies $[9,16]$ who analysed doubles of professional tennis players (lower ranked) at lower ITF international tournaments (previously known as Futures category tournaments), we reached up to 37 $\%$ higher usage of I-formation. This could be explained by the research sample in our study where we examined the top tennis players compared to low ranked players. The reasons of higher usage of Iformation could be in the progress of the doubles tactics in terms of greater activity of the server's partner (at the net) or it could be that these tactics are required at the top tennis level due to very equal game performance of the opposing teams. Changing the tactics to I-formation can build up more pressure on the opponents.
The receiver may be uncertain (the receiver doesn't know, which part of the court will be covered by the server's partner), which can make it difficult for him to hit a return stroke (or can force him to hit his unpopular return - e.g. backhand long line instead of backhand cross court). In the last decade, the Iformation has been popularized by elite players and was implemented into the practice sessions by many coaches. The total absence of the Australian formation in male tennis supports that this Australian formation was substituted by its modern variant I-formation [9, 17]. The I-formation also includes the advantages of the Australian formation; however, the Australian formation indicates in advance which player of the serving team will cover the deuce and ad court, which is not indicated in the I-formation. Therefore, the Iformation may be more efficient than the Australian formation. The Australian formation is still used in female tennis [11]. 
The efficiency of the Classical formation and Iformation was very similar. The question is, why many players apply relatively more difficult I-Formation. The answer may be the tactical need of variability or illegibility (deception) as an additional quality of the game (in addition to fast shots and accuracy). After the second serve, the Classical formation prevailed. This is probably due to the lower serve speed which allows faster and more efficient return stroke and the server's partner has consequently less time to react and to take a correct position.

We tried to analyse the I-formation in detail. In most matches, the frequency and higher efficiency occurred on the deuce court. Conversely, Carboch et al. [11] revealed that players used the I-formation from the ad court more often and with the $85 \%$ efficiency compared to $64 \%$ from the deuce court. One of the reasons why the players use this Iformation from the deuce court may be, that the player (server's partner) poaching at the net can commonly hit a forehand volley winner (can hit the ball harder compared to backhand volley). However, other factors could be involved too.

The I-formation efficiency of right-handed servers had very similar efficiency when serving from the deuce court (89\%) compared to left-handed servers from ad court (90\%); and right-handed players serving from ad court (73\%) vs. left-handed servers from ad court $(72 \%)$ respectively. This may be attributed to specific serve types, which the righthanded servers use from the deuce court, but the left handed servers from the ad court.

The receiving team used the base line position of both players very often, even if returning the second serve. This may be attributed to their preference to start the rally from the baseline and not allowing the opponent to reach a volley winner easily after their return stroke. Nowadays, as we can see high speed serves, the receiver's partner position at the net can be sometimes risky. However, when the second serve is played, the situation is very different as already reported in the results section. This can happen due to lower second serve speed and the receiver can use aggressive (offensive) return. After the first serve fault, the receiving team should use this formation, where the receiver's partner is positioned at the net, otherwise it contradicts with the modern offensive game conception of doubles $[4,9]$.

This study shows a tendency towards higher variability of players' formations while serving or receiving (although only two variants are used either by the serving or receiving team). Players are probably trying to be active and create more difficult conditions for their opponents. Even though the efficiency of these formations is very similar, it can help players focus more on the game while disturbing the stereotypes of their opponents. Currently,

We brought insight and important suggestions for training in the form of "mapping" the game performance from the tactical perspective. However, further use of the results must be made with care. Many other factors also play a role in the tennis match, such as a surface, balls, weather conditions, players' style and their strategies, their serving and returning quality and many more factors affecting the game performance. The limitation of the study was the research sample and size, where the selection of matches may not be a completely representative. Future studies should analyse other variables too, such as the combination of the position of the serving and receiving team including the direction of the serve and return stroke. We recommend recording data of these specific formations when the server misses the first serve. There might be other connections to a subsequent part of the rally after the second serve. We suggest analysing the position of all players on the court at the same time and eventual changes of their position after the first serve fault.

\section{Conclusion}

We analysed the formations of serving and receiving teams at the elite level of doubles. The most important and, in some cases, surprisingly high was the frequency of the I-formation of the serving team. Both I-formation and Classical formation was equally efficient. While returning the first serve, the receiving team also very frequently used the formation of the both players at the base line position and this formation was slightly more efficient compared to the formation when the receiver's partner takes position at the net. These results provide overview of current game performance, tactics and strategies that is used in professional tennis doubles at the top tennis level. The coaches can use the information and adjust the practice sessions according to the tactical demands of professional tennis. 


\section{References}

[1] S.A. Kovalchik, M. Reid, Comparing Matchplay Characteristics and Physical Demands of Junior and Professional Tennis Athletes in the Era of Big Data. Journal of Sports Science and Medicine, 16(4) (2017), 489-497.

[2] R. Martínez-Gallego, J.F. Guzmán, N. James, J. Ramón-Llin, M. Crespo, M.G. Vuckovic, The relationship between the incidence of winners/errors and the time spent in different areas of the court in elite tennis. Journal of Human Sport and Exercise, 8(Proc3) (2013), S601-S607.

https://doi.org/10.4100/jhse.2013.8.Proc3.05

[3] J. Ramón-Llin, J.F. Guzmán, S. Llana, R. Martínez-Gallego, N. James, G. Vuckovic, The Effect of the Return of Serve on the Server Pair's Movement Parameters and Rally Outcome in Padel Using Cluster Analysis, Frontiers in Psychology, 10 (2019) 1-15.

https://doi.org/10.3389/fpsyg.2019.02789

[4] M. Crespo, D. Miley, (1998). ITF Advanced Coaches Manual. ITF, London.

[5] J. Höhm, (1982), Tenis-technika, taktika, trénink [Tennis-technique, tactics, training]. Olympia, Praha.

[6] V. Safarik, (1978), Tenis-vybrane kapitoly [Tennis-selected chapters]. SPN, Praha.

[7] J. Severa, et al. (1993), Ucebni texty pro trenery II. a III. tridy [Manual for tennis coaches - level 2 and 3], CTS, Praha.

[8] D. Lausic, S. Razon, G. Tenenbaum, Nonverbal sensitivity, verbal communication, and team coordination in tennis doubles. International Journal of Sport and Exercise Psychology, 13 (2015) 398-414.

https://doi.org/10.1080/1612197X.2014.993681

[9] L. Cayer, (2004). Doubles tennis tactics. Human Kinetics, Champaign.

[10] J. Carboch, (2009). I-formation in tennis doubles. In M. Pekny \& S. Tvaroh (Eds.). Sport a veda 2009, (pp.174-177). Charles University, Faculty of Physical Education and Sport, Praha,

[11] J. Carboch, T. Kocib, M. Pechacova, Analysis of tactical variants in men's and women's tennis doubles on the international level, Asian Journal of Science and Technology, 5 (2014) 204-207.

[12] W. Black, M. Van de Braam, The Modern Game of Doubles: A Tactical Perspective. ITF coaching and Sport Science Review, 56 (2012) 13-14.

[13] T. Kocib, \& J. Matejka, (2008). Tactics and game conception of tennis doubles at junior and adult level. In J. Dovalil \& M. Chalupecka (Eds.)

Soucasny sportovni trénink (pp.151-155) Olympia, Praha.

[14] R. Martínez-Gallego, M. Crespo, J. Ramón-Llin, S. Micó, J.F. Guzmán, Men's doubles professional tennis on hard courts: Game structure and point ending characteristics, Journal of Human Sport and Exercise, (in press) (2019) https://doi.org/10.14198/jhse.2020.153.13

[15] R.Psotta, (2003). Analyza intermitentní pohybove aktivity: se zvlastnim zretelem ke sportovnim hram [Analysis of intermittent physical activity: with focus to sports games], Karolinum, Praha.

[16] J.Matejka, Porovnání rozdílů ve strategii a taktice tenisove ctyrhry u dorostu a dospelych [Comparation of differences in strategy and tactics of tennis double play between juvenils and adults categories], Charles University, Faculty of Physical Education and Sport, Praha, unpublished Master's thesis, 2007.

[17] J.Carboch, T.Kocib, V.Süss, Taktika a herní pojetí $v$ tenisové ctyrhre [Tactics and strategy in tennis doubles], Studia Kinanthropologica, 14 (2013) 711.

\section{Acknowledgement}

This work was supported by the Charles University, Progress, No. Q41 Biological aspects of the investigation of human movement

\section{Informed consent}

All participants gave written informed consents to participate in this study.

\section{Funding}

This study was not funded by any grant

\section{Conflict of interest}

None of the authors have any conflicts of interest to declare.

\section{About The License}

(C) The author(s) 2020. The text of this article is open access and licensed under a Creative Commons Attribution 4.0 International License. 